\title{
Evaluation of Tension Perpendicular to Grain Strengths in Small Clear Samples of Sugar Maple for Radial,Tangential and 45-Degree Loading Directions
}

\author{
Nilson T. Mascia ${ }^{a *}$ (D), David E. Kretschmann ${ }^{b}$, Aléxia B. Ribeiro ${ }^{a}$ \\ aUniversidade Estadual de Campinas, Rua Saturnino de Brito, 224, Cidade Universitária Zeferino Vaz, \\ 13083-889, Campinas, SP, Brasil \\ ${ }^{b}$ American Lumber Standard Committee, Frederick, Maryland, US
}

Received: May 6, 2019; Revised: May 7, 2020; Accepted: May 12, 2020

\begin{abstract}
The discussion of the importance of the perpendicular tension strength to better understand the wood's mechanical behavior in several situations, such as shrinkage analysis, glued laminated beam failure analysis, has become clear that more basic input information on tension perpendicular to grain is needed. This work investigated tension perpendicular to grain properties in three different orientations, for radial, tangential and 45-degree directions, using Sugar Maple specimens, and testing methodology according to ASTM D143. In addition, the influence of the density on tension strength values for each direction was analyzed. Furthermore, the failure modes of radial, tangential and inclined specimens are shown and a numerical simulation is presented in order to verify the tendency of the ruptures. From the statistical analysis, it can be concluded that the experimental results of tension perpendicular to grain strength loaded in the radial and tangential directions show a significant statistical difference. Strengths obtained at 45-degrees differ significantly from the other directions.
\end{abstract}

Keywords: Tension perpendicular strength, Radial direction, Tangential direction, 45-degree direction, Failure analysis.

\section{Introduction}

The importance of the perpendicular tension strength in understanding the wood's physical a mechanical behavior in several situations, such as shrinkage analysis, failure criterion analysis, glued laminated beam design and others is well known.

Thus, wood shrinkage, for example in a drying process, may be analyzed from the point of view of the influence of stresses in radial and tangential directions of wood and the strengths in these directions. Certain types of ruptures occur when stress generated by drying can reach levels greater than the perpendicular to grain strength, Wood Handbook ${ }^{1}$.

In order to evaluate the design or to verify the structural elements of wood as well, failure criteria are used, as for example, by Mascia and Simoni ${ }^{2}$. The theoretical basis of failure criteria involves the knowledge of the tension perpendicular to grain strengths and, for wood, not only the orthotropic directions but off-axis directions should be taken into account due to the ring orientations and slope of grain combinations.

In this sense, interesting studies, such as Kretschmann et al. ${ }^{3}$ and Fortin-Smith et al. ${ }^{4}$ that have been developed at the USDA (United States Department of Agriculture)-Forest Products Laboratory-Madison, since 2008 to particularly investigate bat breakage in Major League Baseball games in order to reduce the frequency of multi-piece bat failures. It was verified in these studies the influence of excessive slope-of-grain on the bat failures of Sugar Maple (Acer saccharum), an

*email: nilson@fec.unicamp.br important material for use in baseball bats. Also, numerical procedures have been carried out via the finite element method considering various bat profiles.

As a consequence of these studies, more research on wood failure modes and more basic information on wood's mechanical properties versus the grain orientations were shown necessary.

In light of this, it is important to more accurately characterize the tension perpendicular according to the ring orientations. Therefore, it is worth to highlighting a study of Kretschmann ${ }^{5}$ on the Loblolly Pine (P. taeda) tension perpendicular strength, for different ring orientations of the following angles, $0^{\circ}, 22.5^{\circ}, 45^{\circ}, 62.5^{\circ}$ and $90^{\circ}$, illustrated that tension perpendicular to grain is very sensitive to ring orientation, reaching a minimum at the 90 -degree orientation in Loblolly Pine.

Focusing now on structures or structural elements there are several examples related to the tension perpendicular to grain strength. For instance, Franke et al. ${ }^{6}$ reported when the tensile capacity of timber is exceeded, in particular, due to the low tension perpendicular to grain strength, brittle failure occurs, as can be noted in timber beams.

Helandersson and Larsen $^{7}$ pointed out that the importance of knowledge of the tension perpendicular to grain on various elements, such as glued laminated beams, straight or curves ones, in the local vinicity of a joint, with reduced section parts near supports, multiple notches, parts tensioned with notches and so on. It is also noted that Eurocode $5^{8}$ presents an expression that combines both tension perpendicular to 
grain and shear stresses to verify or size the glued laminated timber pieces.

Another issue to be considered in this study is related with the influence of the density on tension perpendicular to grain strength values, obtained with different load orientation, such as, in the radial, tangential and other direction, Kretschmann et al. ${ }^{3}$.

In this context, this research is addressed to evaluate the tension perpendicular to grain and used specimens, ASTM $\mathrm{D} 143^{9}$, in three different orientations, in the radial, in the tangential and in the 45-degree directions and to analyze the influence of the density in these strengths as well. The failure modes of radial, tangential and inclined specimens are shown and a numerical simulation is presented in order to verify the tendency of the ruptures. Furthermore, it is discussed the influence of the anatomical characteristics of Sugar Maple, in particular, the medullary rays on tension perpendicular strength.

\section{Materials and Methodology}

\subsection{Materials and preparaction of specimens}

The Sugar Maple (Acer saccharum) sample to perform this research was collected from Leatherstockings in New York, US.

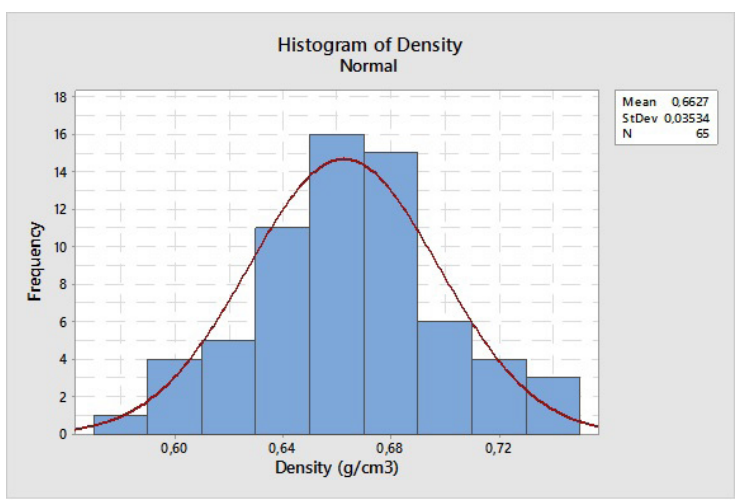

Figure 1. Histogram of the density range of the total specimens.

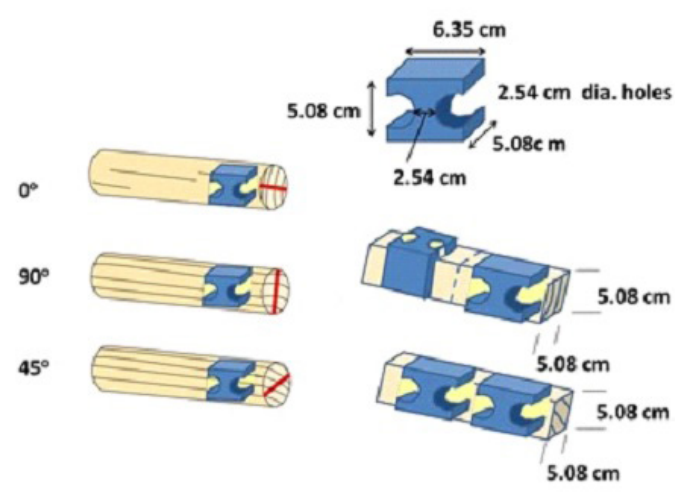

(a)
An inventory of Sugar Maple billets supplied by Leaterstocking (L) was created to assess the overall density distribution for the maple billets. In order to highlight the variation between the densities of the L-group, Figure 1 shows the histogram of the density range for the 65 specimens manufactured for the experimental procedure.

The density range was 0.574 to $0.742 \mathrm{~g} / \mathrm{cm}^{3}$. The average moisture content for the specimens was $13 \%$.

The specimen preparation procedure for the tension perpendicular to grain tests is described as follows. Hard Maple billets that were $6.98 \mathrm{~cm}$ in diameter and 78.74 or $93.98 \mathrm{~cm}$ long were supplied to the carpenter shop at USDA (United States Department of Agriculture)-Forest Products Laboratory-Madison. For 65 billets matched samples were cut up into $5.08-\mathrm{cm}$ by $5.08-\mathrm{cm}$ by $6.35-\mathrm{cm}$ specimens for tension perpendicular to grain testing. For each $0^{\circ}$ and $90^{\circ}$ direction billets, two specimens were cut out, one aligned with rings and other rotated $90^{\circ}$. For each $45^{\circ}$ - direction billet two specimens were manufactured.

The following 5-digit ID code was used to keep track of the each billet and also allowed for later separation of the stocking material. The first digit of the code designated the supplier, i.e., the material from Leatherstockings was represented by an $\mathrm{L}$, the second represents the adopted density category, the third the sequential number assigned the billet when it was inspected, and the last one the ring direction (or loading direction), $\mathrm{R}$ for radial, $\mathrm{T}$ for tangential and for 45-degree orientations denoted by A and B. An example code for each type of ID number is shown in Figure 2, in which for radial direction L112R and for tangential direction L112T and for 45-degree orientations L112A and L112B.

Thus Figure 2 illustrates in the cut out pattern and the labeling convention used for tension perpendicular to grain specimens. A longitudinal-radial-tangential (L-R-T) coordinate system is also inserted to make clear the specimen orientations.

It is worth mentioning that in the specimen preparation procedure, the orientations adopted for the samples were indicated by $0^{\circ}, 45^{\circ}$ and $90^{\circ}$ and were restricted for the cut out procedure purpose. The radial, tangential and $45^{\circ}$-degree orientations used in the tension perpendicular to grain tests are related to the direction of loading in the tensile test according to the labelling convention and as shown in Figure 3.
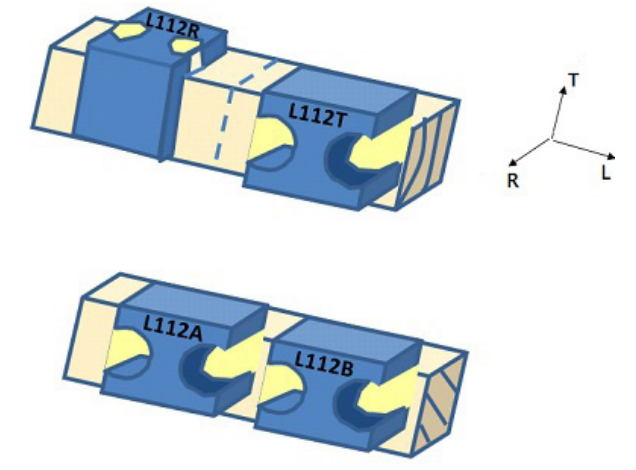

(b)

Figure 2. (a) Cut out pattern for $0^{\circ}, 90^{\circ}$ and $45^{\circ}$-directions; (b) labeling convention for tension perpendicular to grain specimens. 


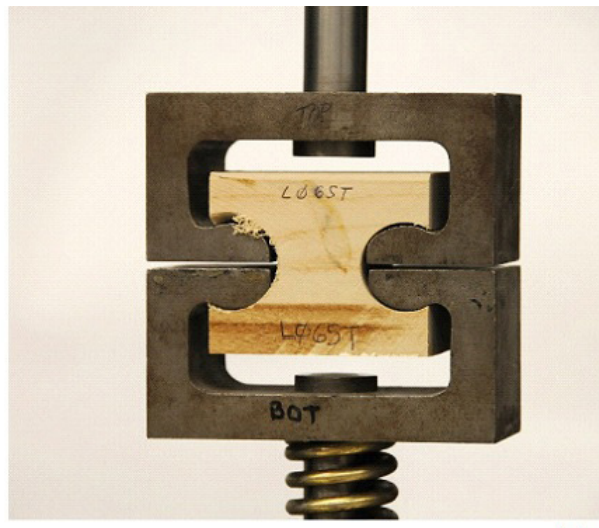

(a)

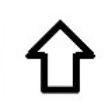

Direction

of

loading
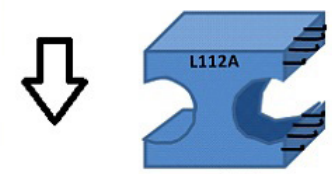

$45^{\circ}$

Radial

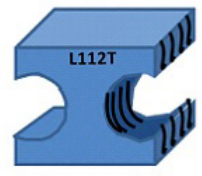

Tangential

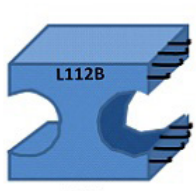

$45^{\circ}$

(b)

Figure 3. The test setup for tension perpendicular to grain testing (a); the direction of loading and specimen orientations (b).

\subsection{Methodology}

\subsubsection{Experimental procedure for tension perpendicular to grain tests}

The tension perpendicular to grain specimens were tested according to ASTM D1439. The tests were conducted on specimens of the size and shape in accordance with Figure 2. The load was applied continuously throughout the test at a rate of motion of the movable crosshead of $2.5 \mathrm{~mm} / \mathrm{min}$ as shown by Figure 4.

\subsubsection{Statistical procedure}

The statistical procedure based on Minitab software ${ }^{10}$ is divided in three steps and provides analyses on: (i) Normality test for a one-sample hypothesis test to determine whether the population from which one draws the sample is normal; (ii) Two-sample t-test for parametric test, the Mann Whitney $\mathrm{U}$ for nonparametric test to compare two continuous-data distributions, including confidence intervals for the difference in means; (iii) Regression analysis to describe the statistical relationship between the predictor and the response variable containing the regression model equation and plot, the variance analysis and the Coefficient of Determination.

\subsubsection{Normality test}

In the Minitab software to proceed the Normality test was chosen the statistic test $p$-value, which is often used in hypothesis tests, where the null hypothesis, which states that the population is normal, is rejected or failed to reject. The smaller the p-value, the smaller is the probability to accept the null hypothesis. It was adopted $p$-value equals to 0.05 to verify the test. Simultaneously to this test, Minitab gives there four options to determine whether the sample data come from a normal population or non-normal, and the Anderson Darling Normality Test was followed. Analogously to $p$-value smaller Anderson-Darling values indicates that the distribution fits the data better.

\subsubsection{Two-sample t-test}

As mentioned to determine whether two populations of $n$ elements have the same population mean, Two-Sample t-test from Minitab software, Ryan and Joiner ${ }^{10}$, was

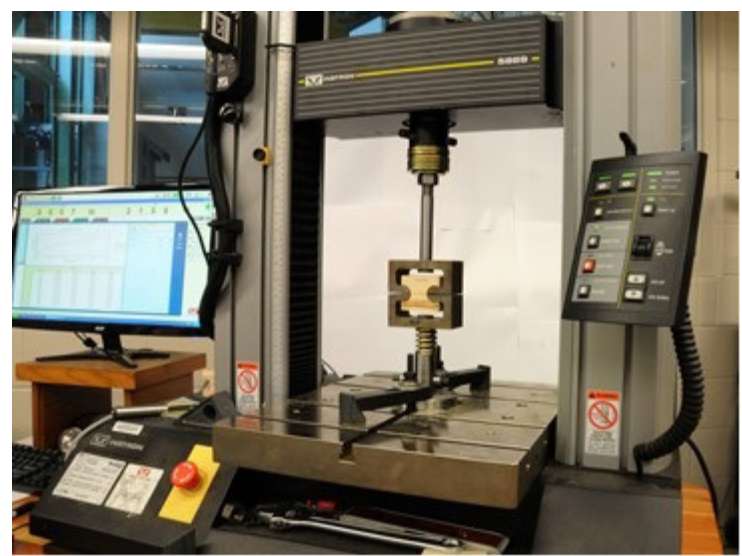

Figure 4. Tension perpendicular to grain loading system.

conducted. For this test, the assumption of the data in each population follows a normal distribution is needed to compare the means of random samples drawn from these two populations. If these assumptions are severely discredited, the nonparametric Mann-Whitney U test, the randomization test may be considered instead. However, it is worth noting that according to Minitab manual it is possible in this situation to use parametric test like Two- sample t-test by not assuming equal variences and also taking into account the sample size, in which each group should have at least 15 elements.

The Two-Sample t-Test verifies the null hypothesis of the two population means $\left(\mu_{1}\right.$ and $\left.\mu_{2}\right)$ is equal or not, i.e., the hypothesis: $\mathrm{H}_{0}: \mu_{1}=\mu_{2}$ versus $\mathrm{H}_{1}: \mu_{1} \neq \mu_{2}$ is tested. This test calculates the following statistics to validate the null-hypothesis:

i) if two samples belong to the same universe, through the expression:

$$
t=\frac{\left(\bar{x}_{1}-\bar{x}_{2}\right)}{\sqrt{\frac{s_{1}^{2}}{n_{1}}+\frac{s_{2}^{2}}{n_{2}}}} \leq t_{\varphi}(p \%)
$$

with: $\bar{x}_{1}$ and $\bar{x}_{2}$ estimate of the averages for the 1 st and the 2nd samples; $s_{1}, s_{2}=$ standard deviations of the 1st and 2nd samples; $n_{1}, n_{2}=$ number of elements of the 1 st and 2 nd 
samples; $t_{\varphi}(p \%)=$ value of t' Student' with $p \%$ for reliability and $(p \%)=$ adopted reliability level.

ii) if the sample averages are statistically equivalent (if the interval of the difference between averages $\mu_{2}$ and $\mu_{1}$ contains the zero), it is determined:

$\Delta_{-}=\left(\bar{x}_{1}-\bar{x}_{2}\right)-t^{*} \sqrt{\frac{s_{1}^{2}}{n_{1}}+\frac{s_{2}^{2}}{n_{2}}} \leq \mu_{2}-\mu_{1} \leq\left(\bar{x}_{1}-\bar{x}_{2}\right)+t^{*} \sqrt{\frac{s_{1}^{2}}{n_{1}}+\frac{s_{2}^{2}}{n_{2}}}=\Delta_{+}$

in which $t^{*}$ is the value corresponding to $p \%$ of reliability. The expression of the freedom degrees $(d f)$ is equivalent to the following:

$$
d f=\frac{\left[\left(\frac{s_{1}^{2}}{n_{1}}\right)+\left(\frac{s_{2}^{2}}{n_{2}}\right)\right]^{2}}{\left[\frac{\left(\frac{s_{1}^{2}}{n_{1}}\right)^{2}}{\left(n_{1}-1\right)}+\frac{\left(\frac{s_{2}^{2}}{n_{2}}\right)^{2}}{\left(n_{2}-1\right)}\right]}
$$

\subsubsection{Mann-Whitney test}

A nonparametric hypothesis test to determine whether two populations have the same population median $(\eta)$. The Mann-Whitney test does not require the data to come from normally distributed populations, but it does make the following assumptions:

- the populations of interest have the same shape,

- the populations are independent.

The confidence interval of $\eta_{1}-\eta_{2}$ is defined as those values of the paired differences for which the null hypothesis is not rejected.

The Mann-Whitney test calculates $U=\min \left(U_{1}, U_{2}\right)$, where:

$$
U_{l}=n_{1} n_{2}+\frac{n_{1}\left(n_{1}+1\right)}{2}-R_{1}
$$

And:

$$
U_{2}=n_{1} n_{2}+\frac{n_{2}\left(n_{2}+1\right)}{2}-R_{2}
$$

and where: $n_{1}$ and $n_{2}$ are the sample sizes, $R_{1}$ and $R_{2}$ are the sum of ranks for observations from sample 1 and 2 respectively.

If the both sample sizes are greater than 10 , the distribution of $U$ can be approximated by a normal distribution. From that the test makes a decision on whether to reject the null hypothesis that the two population medians are equal $\left(\mathrm{H}_{0}: \eta_{1}=\eta_{2}\right)$ or the alternative hypothesis can be left-tailed $\left(\eta_{1}<\eta_{2}\right)$, right-tailed $\left(\eta_{1}>\eta_{2}\right)$, or two-tailed $\left(\eta_{1} \neq \eta_{2}\right)$.

The test statistic $U$ and the $p$-value found by the procedure is compared to the adopted reliability level of 0.05 .

\subsubsection{The regression analysis}

In general, the linear regression model can be written as:

$$
y=\beta_{0}+\beta_{1} x+\varepsilon
$$

and it is supposed that the errors are normally and independently distributed with mean 0 and variance $\sigma^{2}$, or simply, $\varepsilon \approx N I D\left(0, \sigma^{2}\right)$, according to Ryan and Joiner ${ }^{10}$.

The regression analysis can be summarized by the following topics:

i) The test the significance of regression follows the hypothesis:

$$
\begin{aligned}
& H_{0}: \beta_{1}=0 \\
& H_{1}: \beta_{1} \neq 0
\end{aligned}
$$

Using the statistic:

$$
\left|t_{0}\right|>\left|\frac{t_{\alpha}}{2}, n-2\right|,
$$

which implies that the hypothesis $H_{0}: \beta_{1}=0$ is rejected at a desirable percentage of significance, generally, from $5 \%$ until $15 \%$. Thus, it is possible to accept or not the linear model.

Here $n$ is the number of pairs of data, $\alpha$ is the percentage point of significance,

$t_{\alpha / 2, \mathrm{n}-\mathrm{k}}$ is the Student 's distribution and $n-k-1$ are the degrees of freedom.

ii) The analysis of variance is given by the following statistic:

$$
F_{0}=\frac{S S_{R} / 1}{S S_{E} /(n-2)}=\frac{M S_{R}}{M S_{E}}
$$

where: $M S_{R}$ is the regression mean square and $M S_{E}$ is the residual mean square.

To test the hypothesis $H_{0}: \beta_{1}=0$, it is computed the statistical test $F_{0}$ and reject $H_{0}$ if:

$$
F_{0}>F_{\alpha, 1, n-2}
$$

according to certain probability $p$.

Table 1. Summarizes in the test procedure.

It can observe that since the expected means are:

$$
\begin{aligned}
& E\left(M S_{E}\right)=\sigma^{2} \\
& E\left(M S_{R}\right)=\sigma^{2}+\beta_{I}^{2} S_{x x}
\end{aligned}
$$

and $F_{0}$ is defined as the ratio between them, the expected mean squares indicate that if the observed value of $F_{0}$ is large, the slope $\beta_{1}$ is non-zero. The value $p$ quantifies the probability reached.

Table 1. Analysis of the Variance for Significance of Regression.

\begin{tabular}{ccccc}
\hline $\begin{array}{c}\text { Source of Variation } \\
\text { Variation }\end{array}$ & Sum of Squares & Degrees of Freedom & Mean Square & $F_{0}$ \\
\hline Regression & $S S_{R}$ & $k$ & $M S_{R}$ & $M S_{R} / M S_{\mathrm{E}}$ \\
\hline Residual & $S S_{E}$ & $n-k-1$ & $M S_{E}$ & \\
\hline Total & $S_{y y}$ & $n-1$ & & \\
\hline
\end{tabular}


3- Coefficient of Determination

The quantity:

$$
R^{2}=\frac{S S_{R}}{S_{y y}}=1-\frac{S S_{E}}{S_{y y}}
$$

is named the coefficient of determination and explains the proportion of variation of regressor $x$.

\subsubsection{Numerical procedure}

The purpose of the numerical procedure was to verify the maximum tensile stresses to compare with the failure modes for the radial, tangential and inclined specimens, particularly to verify the position where the failure process starts, also confirming the experimental failure configuration.

To develop the numerical analysis a load application apparatus was designed, as illustrated by Figure 5 .

Note in Figure 5 is pictured as a set of three mutually orthogonal axes denoted as the $\mathrm{x}, \mathrm{y}$ and $\mathrm{z}$ axes, those are the global coordinates. The load of $5 \mathrm{kN}$ was applied to the top of the device in the y-direction. It is important to observe that this value is only illustrative, since the study is static linear and the magnitude of the load is irrelevant for the study of the behavior of the stress distribution.

In order to make this global coordinate system compatible with the radial, tangential and $45^{\circ}$-degree orientations used in the tension perpendicular to grain tests, which are related to the direction of loading as presented before in Figure 2 and Figure 3, the following convention was chosen: the y-axis indicates the test loading direction, the $\mathrm{x}$-axis represents transverse direction whereas the z-axis defines in any situation the longitudinal direction, the parallel to fiber direction. For example, for radial orientation specimen, the y-axis represents the radial loading direction (R-axis), whereas the $\mathrm{x}$-axis represents the $\mathrm{T}$-direction (T-axis) and the $\mathrm{z}$-axis the L-direction (L-axis); for the for tangential orientation specimen, the $y$-axis represents the tangential loading direction (T-axis), the $\mathrm{x}$-axis represents the $\mathrm{R}$-direction ( $\mathrm{R}$-axis) and the $\mathrm{z}$-axis the L-direction (L-axis). For the 45-degree orientation, the $\mathrm{y}$-axis and the $\mathrm{x}$-axis are obtained from a 45-degree rotation in the $x-y$ plane, around the $z$-axis, and $\mathrm{z}$ is the L-direction, L-axis.

By taking into consideration the tension perpendicular to grain test specimen and apparatus, the numerical analysis was performed via Ansys ${ }^{\circledR}$ finite element simulations ${ }^{11}$. It involves the following specimen discretization into SOLID186 element $\left(\right.$ Ansys $^{\circledR}$ ) defined by 20 nodes with three degrees of freedom per node, being: translations in three orthogonal axes, i.e., the $\mathrm{x}, \mathrm{y}$ and $\mathrm{z}$ axes.

For the contact surfaces other three elements were used, i.e., TARGE170, CONTA174 and SURF154. The element TARGE170 is used to represent several 3-D target surfaces for the associated contact elements (CONTA173, CONTA174, CONTA175, CONTA17 and CONTA177), with the CONTA174 being specifically used for this analysis. The element CONTA174 is an 8-node element that is intended for general contact analysis. In this analysis, the contact area between two (or more) bodies is generally not known a priori. Finally, the SURF154 is used for any 3-D element area to allow that multiple loads and surface effects can exist simultaneously on a face ${ }^{11}$.

For the specimen's mesh, the workbench Ansys ${ }^{\circledR}$ program-controlled mesh was used, the error limit was set to aggressive mechanical. To define the discretization and the number of finite elements a previous convergence analysis was performed. This method has already been used by Ribeiro and Mascia ${ }^{12}$ on an experimental and numerical research addressed to study the application of a standard test specimens to characterize the shear strength of laminated wood. Finally, the $0.5-\mathrm{mm}$ element size was adopted, in this way, a quality of each element greater than 0.77 was achieved. In the numerical analyses 3010 elements were required (2276 solid elements and 734 contact elements), resulting a total of 12645 nodes.

For the definition of the material properties used in the numerical procedure, the wood species Sugar Maple was designed with orthotropic elastic properties according to the $\mathrm{L}, \mathrm{R}$ and $\mathrm{T}$ axis coordinate system. In order to make this coordinate system compatible with the global system used for the load directions as presented previously in Figure 5, three local coordinates systems were adopted, one for each case studied, i.e. for the radial, tangential and 45-degree specimens. It was noted that for the last specimen its elastic properties were obtained by a 45-degree rotation of the orthotropic axes, $\mathrm{R}$ and $\mathrm{T}$, in the $\mathrm{x}$-y plane, around the $\mathrm{z}$-axis (the L- direction)

The properties needed for modeling are presented in Table 2, in which, $E_{i}$ represents the elastic modulus in each

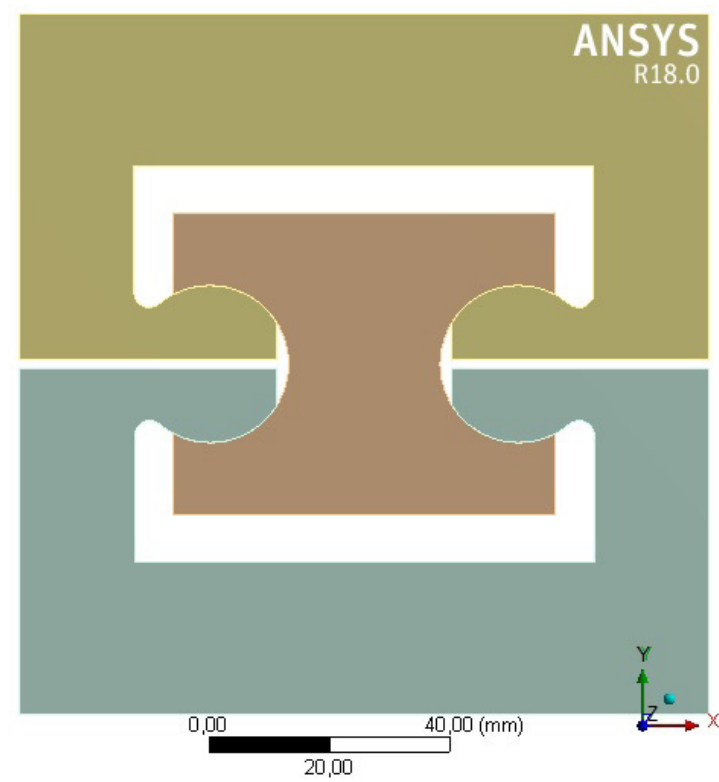

Figure 5. Apparatus used to the numerical analysis.

Table 2. Elastic Properties for Maple sugar (in MPa, except the Poisson's ratios).

\begin{tabular}{ccccccccc}
\hline$E_{R}$ & $E_{T}$ & $E_{L}$ & $G_{R T}$ & $G_{T L}$ & $G_{R L}$ & $v_{R T}$ & $v_{R L}$ & \\
\hline 1991.88 & 980.85 & 15090 & 278.22 & 950.67 & 1674.99 & 0.774 & 0.065 & 0.037 \\
\hline
\end{tabular}


orthotropic direction ( $\mathrm{i}=\mathrm{R}, \mathrm{T}, \mathrm{L}) ; G_{i j}$ is the transversal modulus of rigidity in each plane (ij=RT,TL, RL), and $v_{i j}$ is the Poisson's ratio in each plane (ij=RT,TL,RL). The longitudinal elastic modulus in the L-axis (longitudinal direction) was provided by results of the experimental bending tests according to ASTM D $143^{9}$. The other properties was determined by ratios within the longitudinal elastic moduli for this wood species according to Forest Products Laboratory, Wood Handbook ${ }^{1}$, and also Bodig and Jayne ${ }^{13}$.

\section{Results and Discussion}

\subsection{Histograms of tension perpendicular to grain strengths and Normality Test}

The strength results that were obtained the for tension perpendicular to grain samples of Sugar Maple for radial, tangential and 45-degree A and B loading orientations are presented by Figure 6 to Figure 9. The results were plotted in order to be shown the bias (tendency) of the strength, Ryan and Joiner ${ }^{10}$.

Particularity, Figure 6 and Figure 7 exhibit the histograms of the radial and the tangential tension strengths, while Figure 8 and Figure 9 present the histograms of strengths for the 45-degree A and B loading orientations.

The normality tests using the Minitab statistical software ${ }^{10}$ were performed to determine whether a sample data come from normal population. Table 3 lists the Normality Test results showing that the density, the tangential, the radial tension and 45-A direction strength samples fitted to normal distribution unless the 45-B direction strength sample. It is noted that the density sample fitted to normal distribution according to the same statistical procedure.

\subsection{Comparison among the tension strengths: \\ Two-sample t-test and Mann Whitney U test}

In general, few experimental studies on tension perpendicular to grain are available in the literature. Kretschmann ${ }^{5}$ investigated the influence of percentages of juvenile wood content on shear parallel, compression and tension perpendicular to grain strengths and mode I fracture toughness for loblolly pine, presenting some information on tension-perpendicular to grain strength and the dispersion of the experimental

Table 3. Normality Test Results.

\footnotetext{
1-Normality Test for Radial tension strengths

$\mathrm{N}=65$ results. Mean 10.28 ;St Deviation 2.418

i) $p$-value $=0.560$

ii) Anderson Darling value, $\mathrm{AD}=0.305$

2-Normality Test for Tangential tension strengths

$\mathrm{N}=65$ results. Mean 5.196 ;St Deviation 1.639

i) $p$-value $=0.097$

ii) Anderson Darling value, $\mathrm{AD}=0.630$
}

3-Normality Test for 45-A orientation tension strengths $\mathrm{N}=65$ results. Mean 8.198;St Deviation 2.003

i) $p$-value $=0.120$

ii) Anderson Darling value, $\mathrm{AD}=0.586$

4-Normality Test for 45-B orientation tension strengths

$\mathrm{N}=65$ results. Mean 8.253; St Deviation 2.172

i) $p$-value $<0.005$

ii) Anderson Darling value, $\mathrm{AD}=1.233$

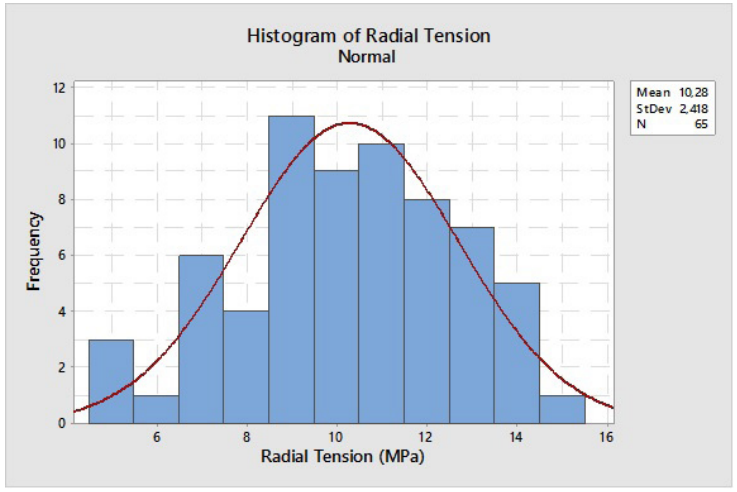

Figure 6. Histogram of Radial Tension Strength.

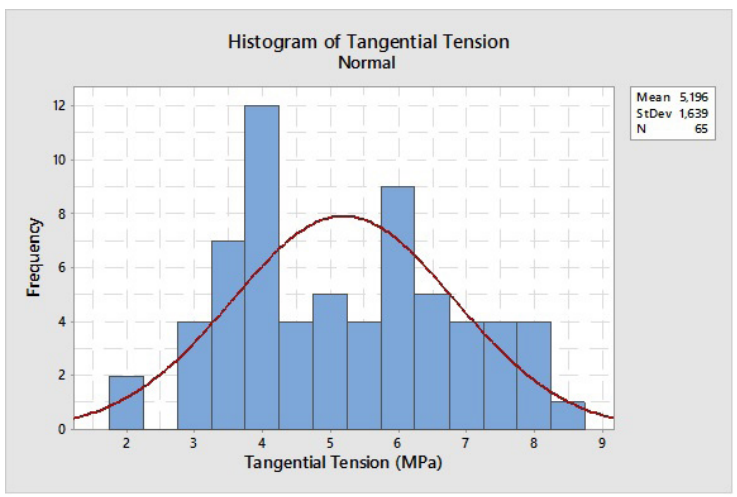

Figure 7. Histogram of Tangential Tension Strength.

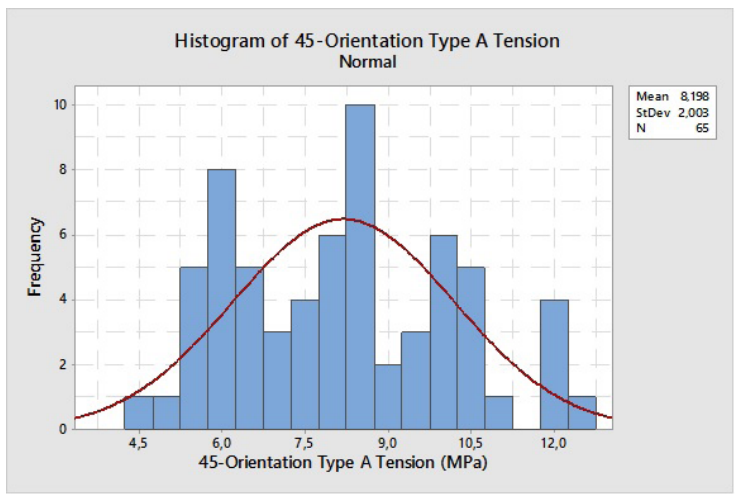

Figure 8. Histogram of 45-degree A Orientation Strength.

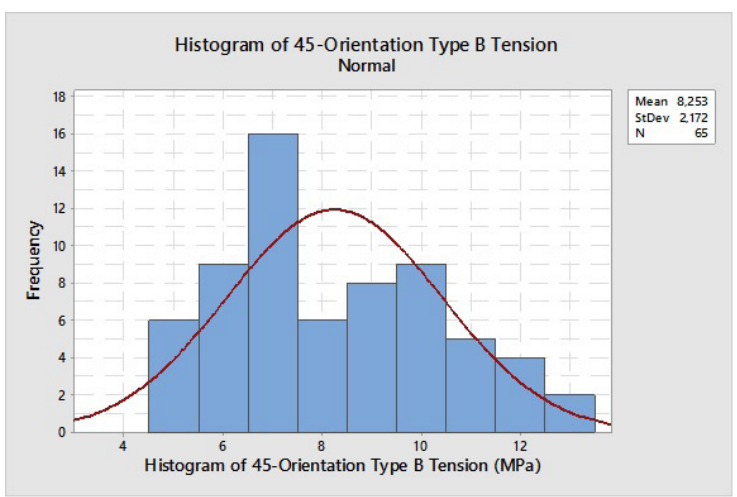

Figure 9. Histogram of 45-degree B Orientation Strength. 
results. Previouly, Gonçalves et al. ${ }^{14}$ provided results of tension perpendicular to grain strength of 14 Eucalytus species that were analized to verify the normal distribution fitting. It was possible to infer that the data exhibit great dispersion and conclude that 6 species did not adjust to the normal distribuiton.

Analogously to these studies, the data presented from Figure 6 to Figure 9 denoted that the tension strengths have a greater dispersion of values and comparisons among the tension strengths via a statistics analysis can demonstrate the relationship of these tension strengths.

Before performing the statistical procedure, it is presented Figure 10 that exhibits the Boxplot summary of matched samples for each loading direction.

From Figure 10 it is possible to point out that the tension perpendicular strength with loading in the tangential direction is almost $50.53 \%$ of the strength when loaded in the radial direction. In addition, the 45-degree orientation for A or B specimen results were located $6.28 \%$ above the mean value between the radial and tangential strength mean value.

By applying a statistics procedure to determine whether two populations of $n$ elements have the same population mean, Two-Sample t-Test and Mann-Whitney Test Minitab software, Ryan and Joiner ${ }^{10}$, were conducted.

Firstly, Table 4 shows the Two-Sample t-Test and CI (Confidence Interval) results obtained for the radial, tangential and 45-degree (A and B) orientation tension strengths and exhibits the results for the t-tests of six combinations. The most important observations that were drawn can be summarized as follows.

Table 4 shows that there is not a statistically significant difference in the mean values between the 45-degree orientation A and B groups. There are however statistically significant differences among the mean values of the tangential, 45-(A and B) orientation, and the radial tension strengths. The difference between groups are greater than would be expected by chance. It is important to notice the

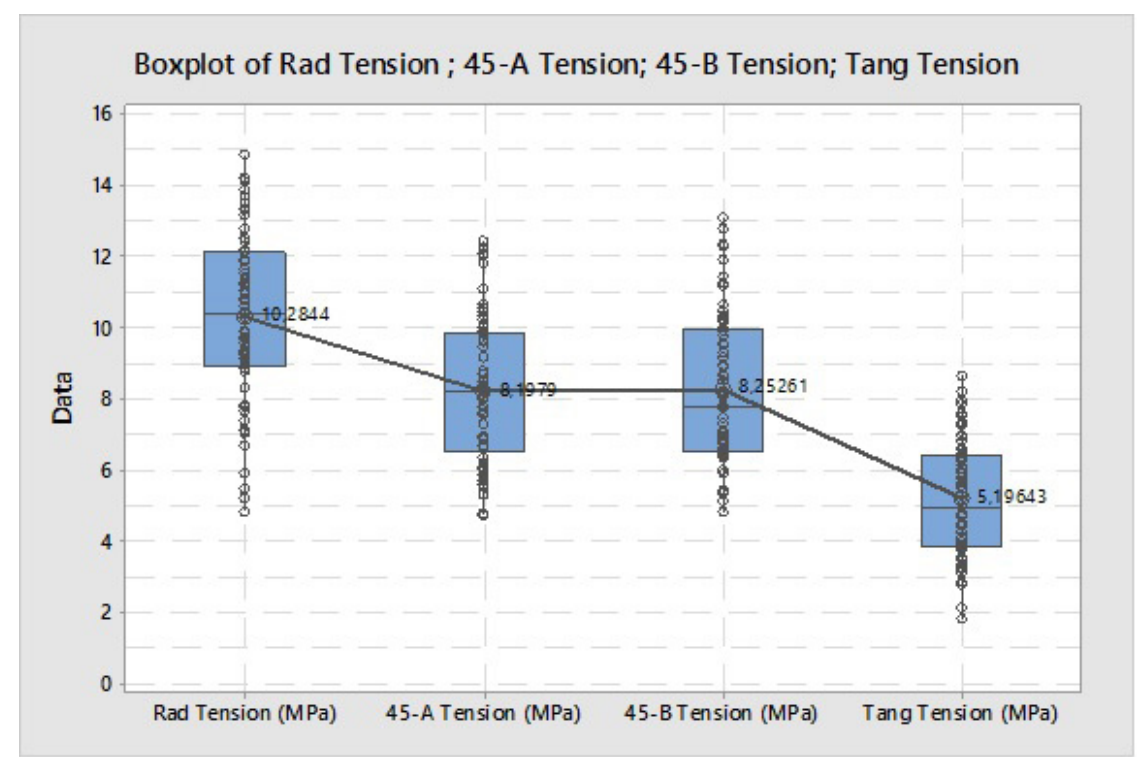

Figure 10. Boxplot of Radial, Tangential and 45-degree (A and B) Orientation Tension Strength.

Table 4. Two-Sample t-Test and CI (Confidence Interval) Results.

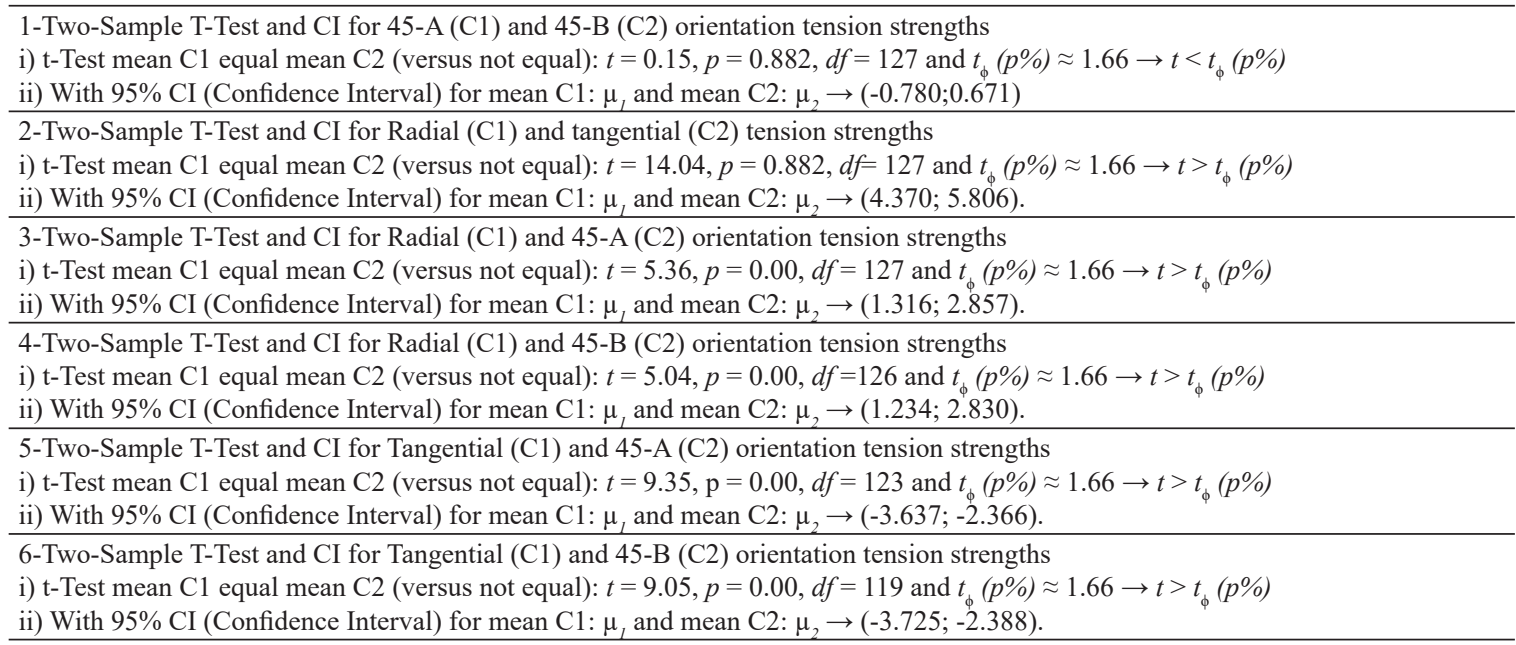


statistically significant difference between the tangential and radial strength values.

Taking into consideration that the Normality Test results listed in Table 3 evidencing that the 45-B direction strength sample fits to a nonnormal distribution, the Mann-Whitney Test is conducted for three combinations of tension strengths related with this tension sample.

Table 5 shows the test results for the 45-degree orientation $\mathrm{A}$ and $\mathrm{B}$ groups demonstrating that the $p$-value is greater than the significance level of 0.05 and the null hypothesis cannot be rejected and, in this way, there is no statistically significant difference between their median values. On the other hand, for the other cases the $p$-values were smaller than 0.05 , therefore, the null hypotheses are rejected and it is evident that there are statistically significant differences between the median values of the $45-\mathrm{B}$ orientation and the tangential and also between the $45-\mathrm{B}$ orientation and the radial tension strengths. These results agreed with to Minitab manual considerations on the use of the nonparametric MannWhitney U test and the parametric test like Two-sample t-Test.

\subsection{Regression analysis of tension strengths}

As verified by the hypothesis tests (Two-Sample t-test and Mann-Whitney $U$ test) there are a high significant difference between the values of the Radial and Tangential tension strengths and less between the Radial (or Tangential)

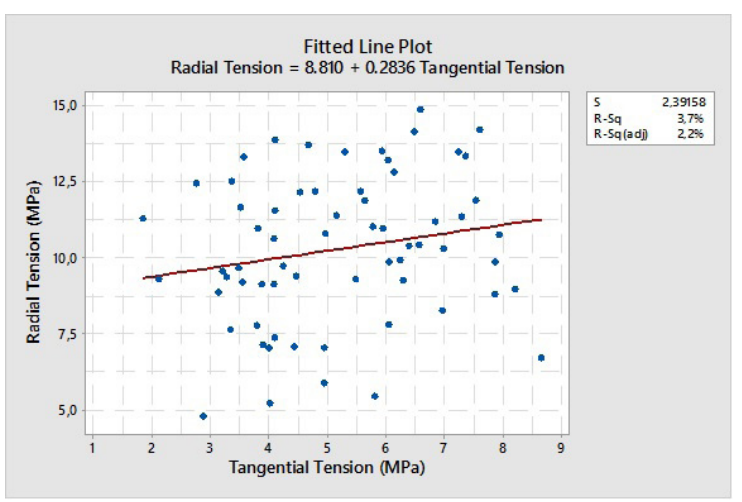

Figure 11. Plotting of the total results for Radial and Tangential Tension Strengths. and the 45-degree (A or B) orientations strengths. Thus, a regression procedure is presented in order to seek to a relationship among these tension strengths addressing to the analysis to the Radial and Tangential tension strengths, and the Radial and 45-degree A tension strengths.

\subsubsection{Regression Analysis: Radial Tension versus Tangential Tension Strengths}

The first analysis relates to radial and tangential relationship as shown by the scatter plot of Figure 11.

The regression analysis yields the following equation for the radial and tangential tension strengths:

Radial Tension $=8.810+0.284$ Tangential Tension

The Analysis of Variance of the regression procedure of Radial Tension and Tangential Tension Strengths is shown in Table 6.

For Table 6 to Table 11, the following notation for the regression analysis was used, according to Ryan and Joiner ${ }^{10}$ : $d f$ is the degree of freedoms; $S$ is an estimate of the standard deviation of the error term in the model; $R-s q$ (or $R^{2}$ ) is the coefficient of determination; $R-s q($ adj) is a modified $R i-s q$ that has been adjusted for the number of terms in the model; $S S$ is the regression mean square; MS is the residual mean square; $F$ is used in hypothesis testing to determine whether two population variances are equal and $p$ is used to analyze whether the regression coefficients are significantly different from zero.

In light of the analysis of variance from Table 6 , it can be drawn that with $p$-value $=0,125$ the regression is not significant with the value $F$ of 2.42 , and the coefficient of determination $R$-sq equals $3.7 \%$ the relationship between the parameters is too small.

\subsubsection{Regression Analysis: Radial Tension versus 45-A orientation Tension Strengths}

The second analysis deals with the radial tension and 45-A orientation relationship as shown by the scatter plot of Figure 12.

The regression equation obtained, by noting that $45-\mathrm{A}$ is substituted by $\mathrm{A}$, is

$$
\text { Radial Tension }=9.101+0.1444 \text { A Tension }
$$

Table 5. Mann-Whitney Test and CI (Confidence Interval) Results.

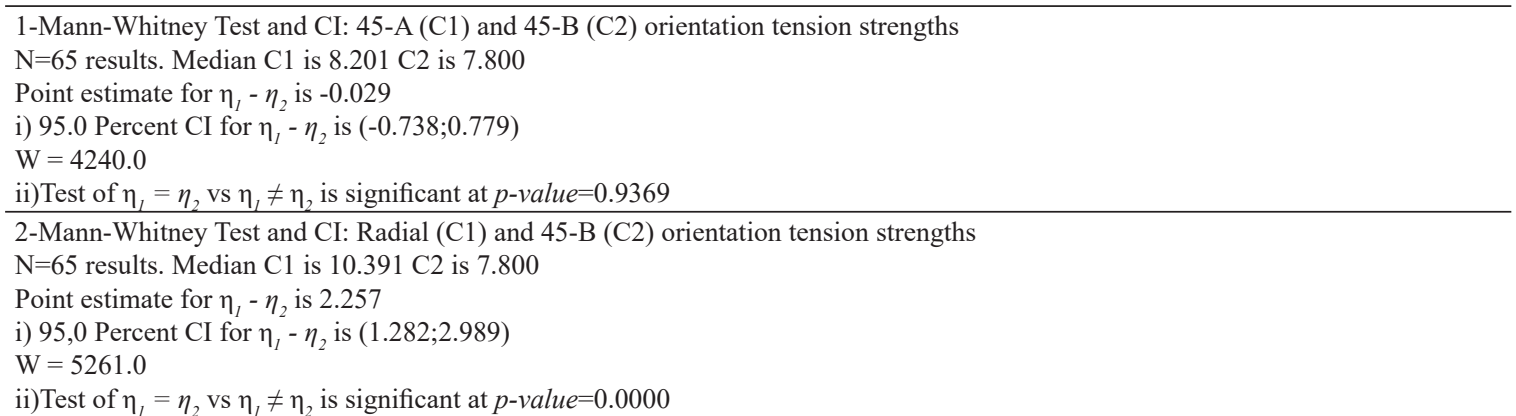

3-Mann-Whitney Test and CI:Tangential (C1) and 45-B (C2) orientation tension strengths

$\mathrm{N}=65$ results. Median $\mathrm{C} 1$ is $4.961 \mathrm{C} 2$ is 7.800

Point estimate for $\eta_{1}-\eta_{2}$ is -2.898

i) 95,0 Percent CI for $\eta_{1}-\eta_{2}$ is $(-3.586 ;-2.273)$

$\mathrm{W}=2717.0$

ii)Test of $\eta_{1}=\eta_{2}$ vs $\eta_{1} \neq \eta_{2}$, is significant at $p$-value $=0.0000$ 


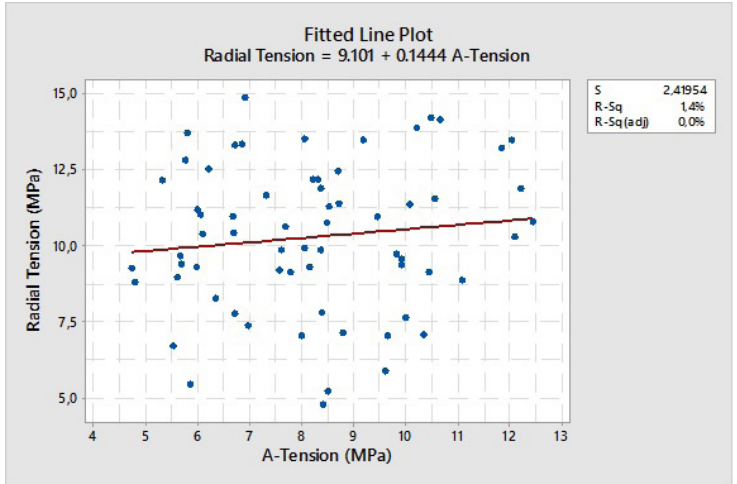

Figure 12. Plotting of the total results for Radial and 45-A Orientation Tension Strengths.

Table 6. Analysis of Variance: Radial Tension versus Tangential Tension Strengths.

\begin{tabular}{|c|c|c|c|c|c|}
\hline Source & $d f$ & $S S$ & $M S$ & $F$ & $p$ \\
\hline Regression & 1 & 13.830 & 13.8302 & 2.42 & 0.125 \\
\hline Error & 63 & 360.337 & 5.7196 & & \\
\hline Total & 64 & 374.168 & & & \\
\hline \multicolumn{6}{|c|}{ Model summary } \\
\hline & $S$ & $R-s q$ & $R$-sq adj & & \\
\hline & 2.39158 & $3.7 \%$ & $2.2 \%$ & & \\
\hline
\end{tabular}

Table 7. Analysis of Variance: Radial Tension versus 45-A Orientation Tension Strengths.

\begin{tabular}{cccccc}
\hline Source & $d f$ & $S S$ & $M S$ & $F$ & $p$ \\
\hline Regression & 1 & 5.355 & 5.35459 & 0.91 & 0.343 \\
\hline Error & 63 & 368.813 & 5.85417 \\
\hline Total & 64 & 374.168 \\
\hline \multicolumn{7}{c}{ Model summary } \\
\hline \multicolumn{7}{c}{$R$-sq } & $R$-sq adj \\
\hline & 2.41954 & $1.4 \%$ & $0.0 \%$ \\
\hline
\end{tabular}

The regression analysis of the radial tension and 45-A orientation tension strengths is shown in Table 7.

Table 7 reveals that with $p=0.343$ the regression is not significant with the value $F$ of 0.91 , and the coefficient of determination $R$-sq equals $1.4 \%$ the relationship between the parameters is too small.

\subsection{Tension perpendicular to grain and density analysis}

The influence of the density on tension strength values obtained is discussed in this item. Based on both Figure 13 to Figure 16 and Table 8 to Table 11 an analysis on the influence of the density on perpendicular to grain strength values in the radial, tangential and 45-degree orientation, for A and B directions, is presented.

\subsubsection{Regression Analysis: Radial Tension Strength versus density}

The next analysis refers to the radial tension and 45-A orientation relationship as shown by the scatter plot of Fig 13, showing a minimal trend towards increasing radial tension perpendicular to grain strength with increasing density.

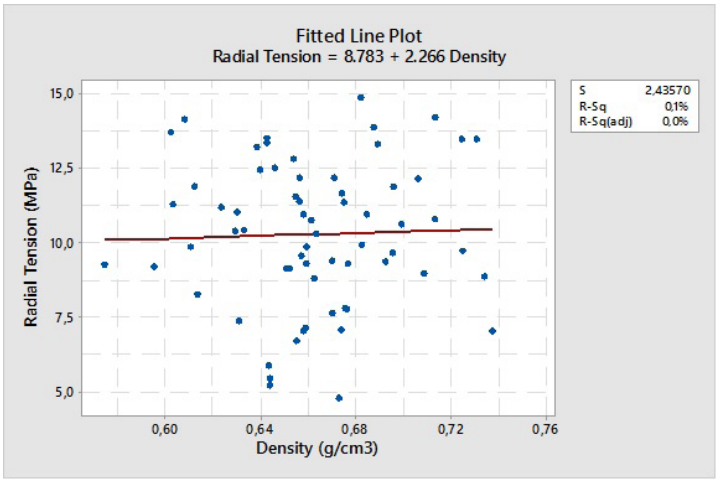

Figure 13. Plotting of the results for Radial Tension Strength and Density.

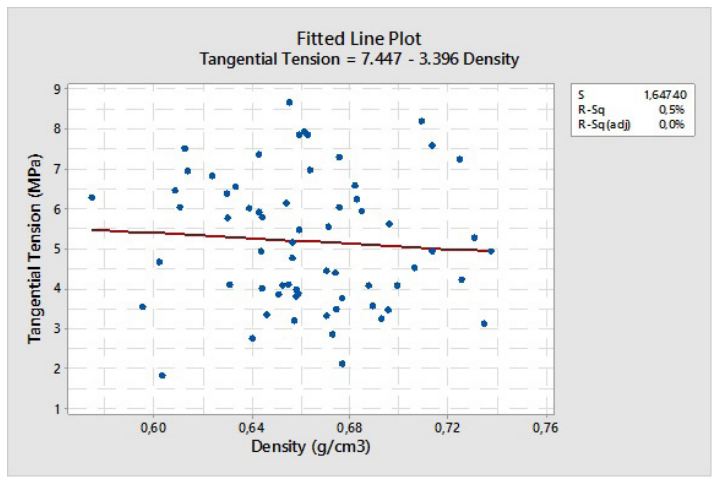

Figure 14. Plotting of the results for Tangential Tension Strength and Density.

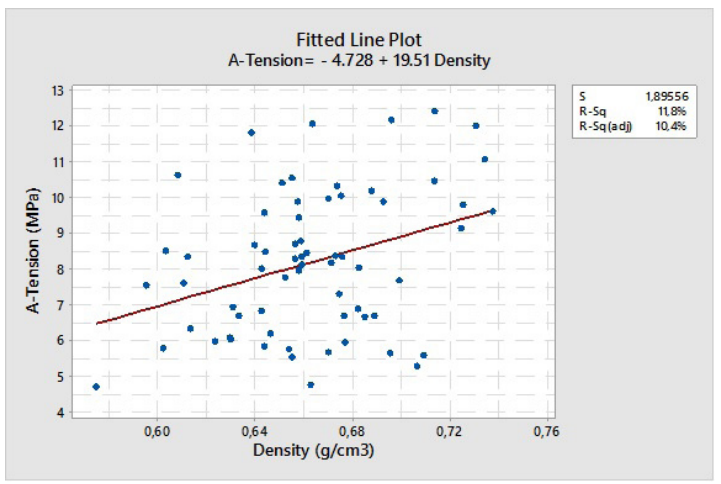

Figure 15. Plotting of the results for the 45-A Orientation Tension Strength and Density.

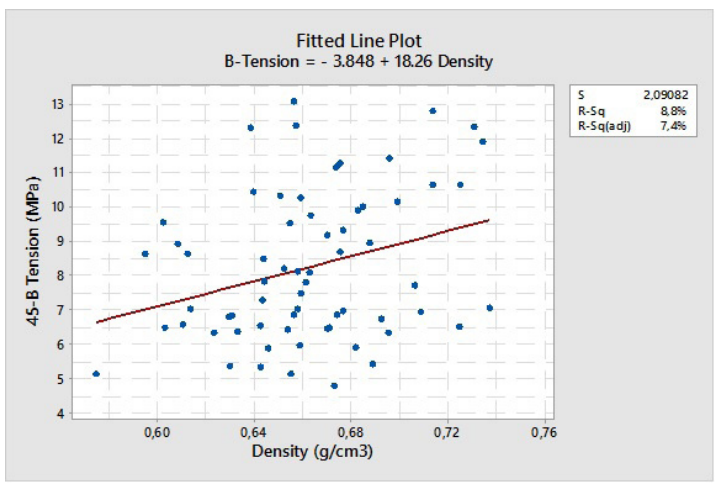

Figure 16. Plotting of the results for the 45-B Orientation Tension Strength and Density. 
Table 8. Analysis of Variance: Radial Tension Strength versus Density.

\begin{tabular}{cccccc}
\hline Source & $d f$ & $S S$ & $M S$ & $F$ & 0.07 \\
\hline Regression & 1 & 0.410 & 0.4104 & 0.793 \\
\hline Error & 63 & 373.757 & 5.9327 & \\
\hline Total & 64 & 374.168 & \\
\hline \multicolumn{7}{c}{ Model summary } \\
\hline \multicolumn{7}{c}{$R-s q$} & $R$-sq adj \\
\hline
\end{tabular}

Table 9. Analysis of Variance: Tangential Tension Strength versus Density.

\begin{tabular}{|c|c|c|c|c|c|}
\hline Source & $d f$ & $S S$ & $M S$ & $F$ & $p$ \\
\hline Regression & 1 & 0.922 & 0.9218 & 0.34 & 0.562 \\
\hline Error & 63 & 170.978 & 2.7139 & & \\
\hline Total & 64 & 171.900 & & & \\
\hline \multicolumn{6}{|c|}{ Model summary } \\
\hline & $S$ & $R-s q$ & $R$-sq adj & & \\
\hline & 1.64740 & $0.54 \%$ & $0.00 \%$ & & \\
\hline
\end{tabular}

Table 10. Analysis of Variance: 45-A Orientation Tension Strength versus Density.

\begin{tabular}{|c|c|c|c|c|c|}
\hline Source & $d f$ & $S S$ & $M S$ & $F$ & $p$ \\
\hline Regression & 1 & 30.41 & 30.413 & 8.46 & 0.005 \\
\hline Error & 63 & 226.37 & 3.593 & & \\
\hline Total & 64 & 256.78 & & & \\
\hline \multicolumn{6}{|c|}{ Model summary } \\
\hline & $S$ & $R-s q$ & $R$-sq adj & & \\
\hline & 1.89556 & $11.84 \%$ & $10.44 \%$ & & \\
\hline
\end{tabular}

Table 11. Analysis of Variance: 45-B Orientation Tension Strength versus Density.

\begin{tabular}{|c|c|c|c|c|c|}
\hline Source & $d f$ & $S S$ & $M S$ & $F$ & $p$ \\
\hline Regression & 1 & 26.6541 & 26.654 & 6.10 & 0.016 \\
\hline Error & 63 & 275.41 & 4.372 & & \\
\hline Total & 64 & 302.06 & & & \\
\hline \multicolumn{6}{|c|}{ Model summary } \\
\hline & $S$ & $R-s q$ & $R-s q$ adj & & \\
\hline & 2.09082 & $8.82 \%$ & $7.38 \%$ & & \\
\hline
\end{tabular}

The obtained regression equation is:

$$
\text { Radial Tension }=8.78+2.27 \text { Density }
$$

Table 8 presents the regression analysis of the radial tension strengths and densities considering the plotting data of Figure 13.

Taking into account the analysis of variance from Table 8 , it can be inferred that with $p=0.793$ the regression is not significant with the value $F$ of 0.07 , and the coefficient of determination $R^{2}-s q$ equals $0.11 \%$ the relationship between the parameters reveals significantly small.

\subsubsection{Regression Analysis: Tangential Tension Strength versus density}

The regression analysis of tangential tension strengths and densities is shown in Table 9 considering the plotting data of Figure 14. This figure demonstrates that the impact of density on the tangential tension perpendicular to grain strength is minimal as the radial tension strength.
From the regression analysis the following equation is obtained:

$$
\text { Tangential Tension }=7.447-3.396 \text { Density }
$$

and Table 9 shows the regression analysis of the tangential tension strengths and densities.

From Table 9 with $p=0.562$ implies that the regression is not significant with the value $F$ of 0.34 , and the coefficient of determination $R s q$ equals $0.54 \%$ the relationship between the parameters is significantly small.

\subsubsection{Regression Analysis: 45-A orientation tension strength versus density}

The regression analysis of the 45-A orientation tension strengths and densities is shown in Table 10 considering the plotting data of Figure 15.

Figure 15 suggests that as density increases so does the tension perpendicular to grain strength of the A samples. 


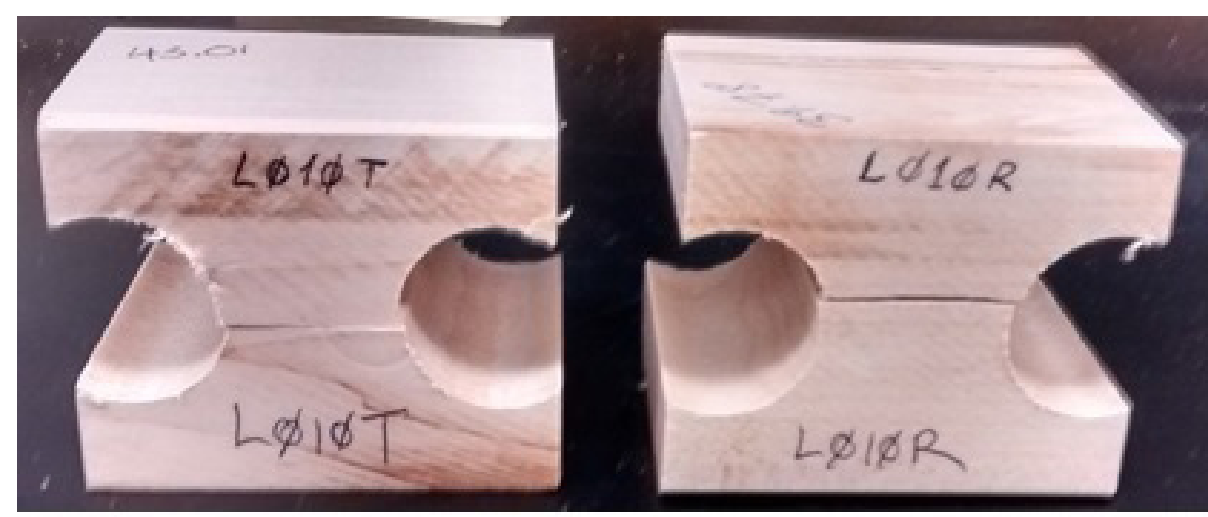

(a)

(b)

Figure 17. Typical failure mode in tangential and radial specimens in tension perpendicular to grain tests.

The regression equation for the 45 -A orientation tension strengths and densities is:

$$
A-\text { Tension }=-4.728+19.51 \text { Density }
$$

and Table 10 summarizes the analysis of variance.

Based on Table 10, it can be drawn that with $p=0.005$ the regression is significant with the value $F$ of 8.46 and the coefficient of determination $R^{-} s q$ equals $11.84 \%$ but the relationship between the parameters is small.

\subsubsection{Regression Analysis: 45-B orientation tension strength versus density}

The regression analysis of the 45-B orientation tension strengths and densities is shown in Table 11 considering the plotting data of Figure 16. Following the same trend of the 45-A orientation tension strengths Figure 16 suggests that as density increases so does the tension perpendicular to grain strength of the B samples.

The regression analysis yields the following equation, by noting that B substitutes 45-B:

$$
B-\text { Tension }=-3.848+18.26 \text { Density }
$$

and Table 11 summarizes the analysis of variance.

The analysis of variance from Table 11 indicates that with $p=0.016$ the regression is significant with the value $\mathrm{F}$ of 6.10 and the coefficient of determination $R$ s $s$ equals $8.82 \%$ but the relationship between the parameters is small.

It is noted that from the statistical analysis developed in this item the influence of the density on perpendicular to grain strength values in radial and tangential directions can be considered not significant (even that it is not possible to reject the null hypothesis) for radial and tangential tension perpendicular to grain. On the other hand, in the cases of the 45-degree orientation specimens (types A and B) certain relationship is noted.

\subsection{Failure modes verified}

The failure modes of radial, tangential and inclined specimens were the typical separation by tension of the fibers. In addition, the effects of shear stresses in inclined

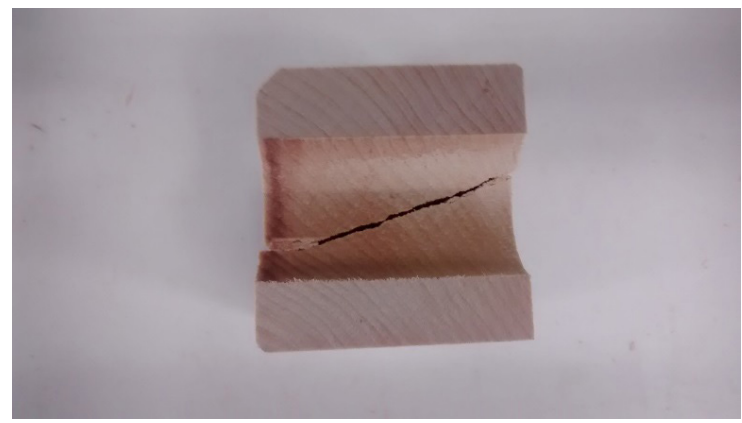

Figure 18. Typical failure mode of 45-degree direction specimen in perpendicular tension perpendicular to grain tests.

specimens due to positioning of the fibers in relation to the applied stress were observed.

Figure 17 illustrates an example for radial or tangential tension perpendicular to grain specimen whereas Figure 18 an example of such failure modes for 45-degree orientation specimen.

According to Bodig and Jayne ${ }^{13}$ due to the non-uniform normal stress distribution acting in the tension perpendicular to grain specimen the ultimate tensile strength of wood in this direction is grossly underestimated, but, on the other hand, the specimens fail, in general, in the vicinity of the plane of least cross-sectional area. The numerical analysis presented as follows makes these comments evident.

\subsection{Numerical analysis}

The purpose of the numerical procedure was to find the maximum tensile stresses to compare with the failure modes for the radial, tangential and inclined specimens, particularly to verify the position where the failure process starts, also confirming the experimental failure configurations.

In this context, the normal stress distributions were elaborated using SAS $2009^{11}$ and shown by Figure 19 to Figure 21. These figures illustrate the region where the maximum tensile stresses were found. From Figure 19 and Figure 20, it is verified that such stresses occur at the edges of the central section and acting parallel to the loading axis (the y-axis) while Figure 21 evidences that maximum 


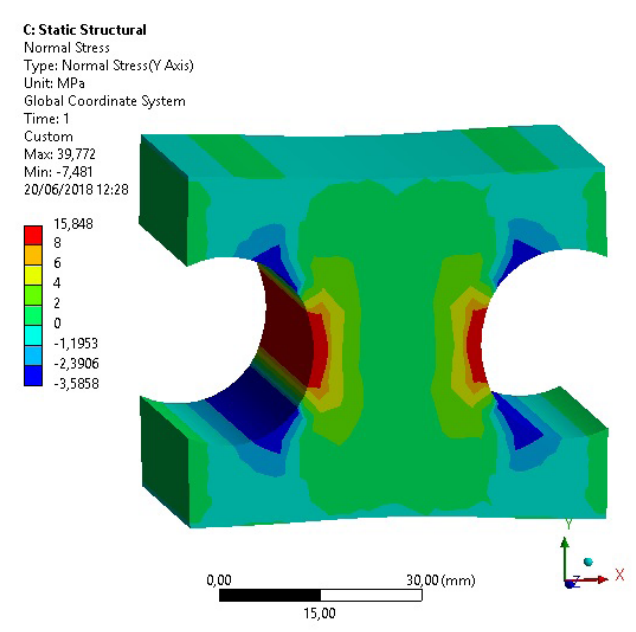

Figure 19. Normal stress distribution for radial specimen in tension perpendicular to grain tests.

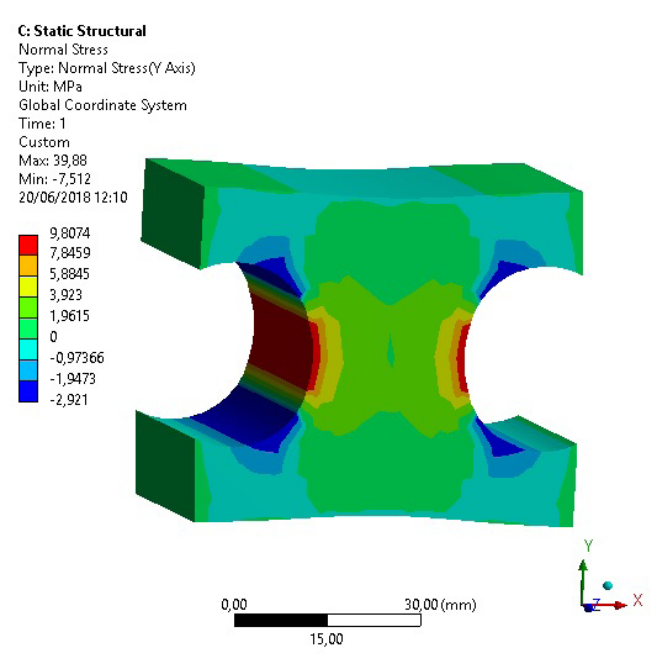

Figure 20. Normal stress distribution for tangential specimen in tension perpendicular to grain tests.

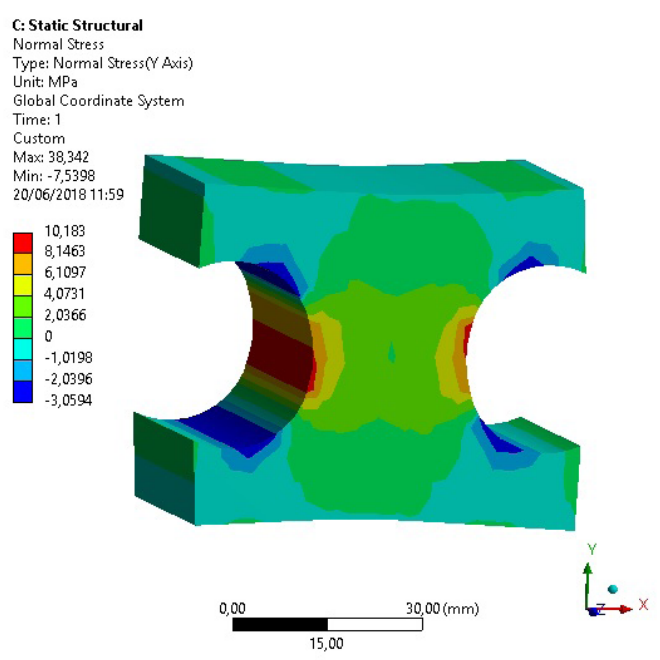

Figure 21. Normal stress distribution for 45-orientation specimens (A or B) in tension tests. stresses were distributed at the edges as well but run inclined in relation to the loading axis.

These numerical results confirmed the experimental failure configurations presented previously by Figure 17 and Figure 18, also indicating the region where the failure process was started.

Examining the radial and tangential failure modes, the typical failures were related to tension failure in the earlywood (juvenile wood) region and probably with the strength contribution of the medullary rays (as discussed in the next item), and for the inclined samples, the tension failure is also accompanied by shear failure along a growth ring. Similar results were verified by Kretschmann ${ }^{5}$ and Bodig and Jayne ${ }^{13}$.

\section{Influence of Medullary Rays in Tension Perpendicular to Grain Strength}

As the test results indicated that the tension perpendicular strength in the tangential direction is almost half the strength when loaded in the radial direction, it is obvious that can be related to the influence of the medullary rays on this wood's mechanical property.

In technical literature, there are many studies demonstrating that the presence of wood rays increases the strength in the radial direction and also can alter other orthotropic directions. For instance, Ashby and Mehl ${ }^{15}$ analyzed the mechanical behavior of a piece of wood, under compressive stresses, at a cellular level to evaluate the influence of the positioning of the medullary rays on the wood strengths in the three orthotropic directions. It was observed that the presence of wood rays caused an increase mainly in radial strength.

Also, Zauner ${ }^{16}$ took microscopic images using computed tomography to examine the orthotropic planes of the following wood species, Spruce Norway, Picea Abies [L.] and European Beech, Fagus sylvatica [L.], the former is a conifer while the latter is a hardwood. Zauner ${ }^{16}$ verified the rupture of medullary rays and the importance of their presence in wood strength in compression and tension tests.

Burget and Eckstein ${ }^{17}$ stated for the medullary ray strength a significantly high value of about $75 \mathrm{MPa}$, rated by micro tension test in low humidity conditions, highlighted the importance of underestimating the strength of medullary ray, basically constituted by the parenchyma, in wood strength. Also was reported that the proportion of the medullary rays in the composition of wood can range from 8 to $40 \%$ for various species. In addition, it was noted that the strength in the radial direction is greater than in the tangential direction.

Burget et al. ${ }^{18}$ drawing attention to the stiffening and strengthening influence of medullary rays in radial direction reported that, higher values of the mechanical properties in radial direction compared to the tangential can induced the mechanical behavior of wood in the orthotropic direction properties.

Furthermore, Burget et al. ${ }^{18}$ reported that the presence and proportion in volume of medullary rays in the wood of the studied species may influence the wood stiffness in the radial direction, regardless of its size. Thus, the radial modulus of elasticity is dependent of the volume fraction of rays and the apparent density of wood as well. In the tangential direction, 


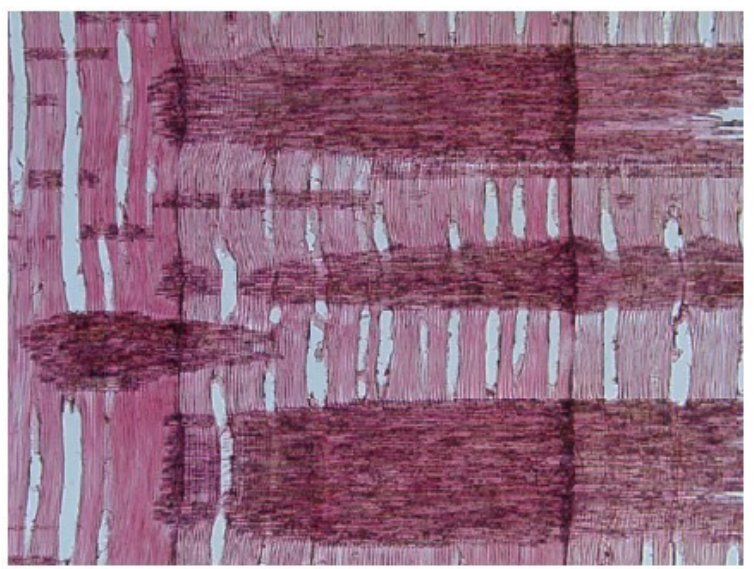

(a)

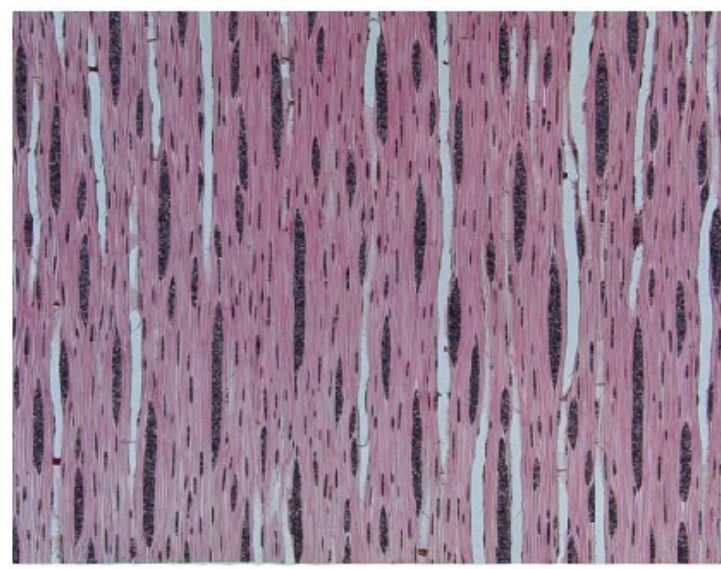

(b)

Figure 22. The amount of medullary rays on the radial-longitudinal (a) and tangential-longitudinal (b) planes of Sugar Maple wood species. (Images courtesy of Alex Wiedenhoeft).

the apparent density is the factor that influences the wood stiffness, the elastic modulus for example.

Focusing on this present research, in which Sugar Maple (Acer saccharum) was used, and considering Figure 22a and Figure 22b, whose images were provided by a researcher from Forest Products Laboratory-Madison, Alex Wiedenhoeft, show the radial-longitudinal plane (the radial direction is the horizontal direction, and the longitudinal direction is the vertical one) and the tangential-longitudinal plane (the tangential direction is the horizontal direction, and the longitudinal direction is the vertical one) of this wood species, a significant presence of medullary rays can be noted.

The estimated percentage of the volume of medullary rays in relation to the volume of the timber is about $17.9 \%$, according to Alex Wiedenhoeft, and this number of rays certainly contributed to increase the tension perpendicular to grain strength in radial direction when compared to tangential direction.

\section{Conclusions}

An experimental study investigating the tension perpendicular to grain properties, using Sugar Maple specimens and testing methodology according to ASTM D143 ${ }^{9}$, was developed.

The analysis of the obtained results shown that the density, the tangential, the radial tension and 45-A direction strength samples fitted to normal distributions whereas the 45-B direction strength sample revealed tendency towards a nonnormal distribution.

From the statistical analysis, it can be concluded that the results obtained for tension perpendicular to grain strengths, in the radial, tangential and 45-degree directions, exhibited a significant statistical difference between each other. The substantial ray packets of Sugar Maple can explain these differences.

In addition, it is important to note that the influence of the load direction on the tension perpendicular to grain strength and to verify whether this is considered in technical codes as well. For example, ASTM $143^{9}$ and Bodig and Jayne ${ }^{13}$ indicate the radial load direction whereas the ABNT - NBR $7190^{19}$ the tangential direction to evaluation this strength.
Also, the density did not have a statistically significant influence on the perpendicular to grain strength values in radial and tangential directions. There was very little effect of influence of density on the tangential perpendicular to grain strength but there was a tendency for increased radial tension perpendicular to grain strength with increased density. Density had an even stronger influence on the 45-degree inclined specimens.

Regarding the radial and tangential failure modes, it was observed that the typical failures were related to tension failure in the earlywood (juvenile wood) region of the specimens and probably with the strength contribution of the medullary rays, and for the inclined specimens, the tension failure is accompanied by shear failure along a growth ring.

In general, this work intended to contribute with the knowledge of the tension perpendicular to grain behavior.

\section{Acknowledgement}

The authors thank Sara Fishwild and Timothy Nelson from the Forest Products Laboratory-Madison, Wisconsin-US for her assistance in sample testing, and Fapesp, Sao Paulo Research Foundation, Brazil (Project number 2014/23818-1), for the financial support to develop this research.

\section{References}

1. Forest Products Laboratory. Wood handbook: wood as an engineering material: general technical report FPL-GTR-190. Madison: Forest Products Laboratory, Forest Service, U.S. Department of Agriculture; 2010. 508 p.

2. Mascia NT, Simoni RA. Analysis of failure criteria applied to wood. Eng Fail Anal. 2013;35:703-12.

3. Kretschmann DE, Bridwell JJ, Nelson TCV. Effect of changing slope of grain on ash, maple, and yellow birch bending strength. In: Proceedings of the 11th World Conference on Timber Engineering (WCTE 2010); 2010 June 20-24; Riva Del Garda, Italy. Red Hook, NY: Engineered Wood Products Association; 2010. p. 1-10.

4. Fortin-Smith J, Sherwood J, Drane P, Kretschmann D. Characterization of maple and ash material properties for the finite element modeling of wood baseball bats. Appl Sci. 2018;8(11):2256. http://dx.doi.org/10.3390/app8112256.

5. Kretschmann DE. Influence of juvenile wood content on shear parallel, compression, and tension transverse to grain strength and mode I fracture toughness for loblolly pine: research paper 
FPL-RP-647. Madison: Forest Products Laboratory, Forest Service, U.S. Department of Agriculture; 2008. 25 p.

6. Franke S, Franke B, Harte AM. Failure modes and reinforcement techniques for timber beams - State of the art. Constr Build Mater. 2015;97:2-13. http://dx.doi.org/10.1016/j.conbuildmat.2015.06.021.

7. Helandersson S, Larsen HJ. Timber engineering. UK: Wiley; 2003. $427 \mathrm{p}$.

8. European Committee for Standardization. Eurocode 5: design of timber structures: part 1.1: general rules and rules for buildings. Bruxelas: CEN; 2004. 110 p.

9. American Society for Testing and Materials - ASTM. ASTM D143: standard test methods for small clear specimens of timber. Philadelphia: ASTM; 2014.

10. Ryan BF, Joiner BL. Minitab 5: Minitab handbook. Belmont: Duxbury Press; 1994.

11. Swanson Analysis Systems - SAS. ANSYS reference manual (version 12). Houston: SAS; 2009.

12. Ribeiro A, Mascia NT. Numerical and experimental study of shear stress behavior of NBR and ASTM standard test specimens for FRP-wood bonds. Compos Struct. 2019;224:111066. http:// dx.doi.org/10.1016/j.compstruct.2019.111066.

13. Bodig J, Jayne BA. Mechanics of wood and wood composites. New York: Van Nostrand; 1982. 430 p.

14. Gonçalves R, Lahr FAR, Frigério GP. Introdução ao estudo da distribuição de freqüência da resistência à tração normal às fibras em algumas espécies de eucalipto. In: Anais do IV Encontro Brasileiro em Madeira e em Estruturas de Madeira; 1992; São Carlos. São Carlos: USP; 1992. p. 105-122.

15. Ashby MF, Medalist RFM. The mechanical properties of cellular solids. Metall Trans, A, Phys Metall Mater Sci. 1983;14(9):175569. http://dx.doi.org/10.1007/BF02645546.

16. Zauner M. In situ synchrotron based tomographic microscopy ETH uniaxially loaded wood: in-situ testing device, procedures and experimental investigations [dissertation]. Zürich: ETHZürich; 2014.

17. Burgert I, Eckstein D. The tensile strength of isolated wood rays of beech (Fagus sylvatica L.) and its significance for the biomechanics of living trees. Trees. 2001;15(3):168-70. http:// dx.doi.org/10.1007/s004680000086.

18. Burgert I, Bernasconi A, Niklas KJ, Eckstein D. The influence of rays on the transverse elastic anisotropy in green wood of deciduous trees. Holzforschung. 2001;55(5):449-54. http:// dx.doi.org/10.1515/HF.2001.074.

19. Associação Brasileira de Normas Técnicas-ABNT. NBR 7190: brazilian code for timber structures: projeto de estruturas de madeira. Rio de Janeiro: ABNT; 1997. 107 p. 